\title{
BIM Model Integration of Concrete and Steel Structures in Assembled Substations
}

\author{
Ying Xu, Jinwei Zhang, Dongliang Li and Cuiling Ao \\ Research Institute of Economics and Technology of State Grid Jibei Electric Power Co. Ltd., China
}

Keywords: Assembled substation, BIM model, Concrete structure, Steel structure, Fineness.

\begin{abstract}
Application of BIM technology in the construction of assembly substation is the trend of construction industrialization and informatization in power grid industry. Assembled substation is composed of concrete structure and steel structure. In the process of building refined BIM model, two different models built by Revit and Tekla are integrated into Navisworks through IFC data exchange format. The results show that when Tekla model exports IFC files, the Coordination View 1.0 or Surface geometry format is selected to maintain the integrity of the model imported into Revit; Revit model is exported to *.nwc format, and model in Tekla is exported to IFC format, which can be imported into Navisworks for integration model and using. According to the characteristics of assembled substation, the efficiency and fineness of BIM model can be significantly improved by using a variety of software hybrid modeling methods.
\end{abstract}

\section{Introduction}

At present, the application of BIM technology in assembly building in China is still in its infancy. Most enterprises mainly use software to model when applying BIM technology, such as Revit, Bentley, Tekla, MagiCAD, etc. However, all kinds of software have their own application conditions and characteristics, and there are also model data interfaces among them ${ }^{[1]}$. The domestic PKPM-BIM adopts the idea of structural design in the design of prefabricated components, which is slightly different from other design software ${ }^{[2]}$. Therefore, how to make full use of the characteristics of all kinds of software and improve the precision and efficiency of modeling has become an urgent problem to be solved in BIM modeling of assembly building. This paper mainly discusses how to use different modeling software of concrete structure and steel structure for hybrid modeling in the overall modeling of assembly substation, in order to improve the efficiency and precision of modeling, and finally integrate the models into the same platform for effective use.

\section{Construction of BIM Model}

Taking a $220 \mathrm{KV}$ substation as an example, the hybrid modeling and model integration methods are discussed. The substation construction site contains four main units: two power distribution plant buildings, two main substation electric fields, pump house, water tank and guard room. Accident oil tank, septic tank, lightning rod, road, cable trench, fence and other structures can be used as part of site modeling. In monolithic buildings, prefabricated steel components are used in the structure design of distribution plant buildings. Complex steel truss beams are installed on the main transformer fire wall. Prefabricated PC components are used to install and pour the three walls around the site. Variable structural forms make the modeling work more complex.

Combining with the characteristics of this project's assembly building, a variety of software models are finally determined, and finally the research ideas of modeling in different software are established. The building parts of the site and its subsidiary facilities, guard room and distribution device building are modeled by Revit software. The steel structure part of the main transformer station and the structure part of the distribution device building are modeled by Tekla software. After the modeling work is completed, Tekla steel structure model is exported through IFC format and integrated into Revit for component modification and model rendering roaming; Revit and Tekla model are integrated into Navisworks to prepare for model entry into the platform. 


\section{Hybrid Modeling Method for Concrete and Steel Structures}

According to the above BIM modeling ideas, the hybrid modeling method of concrete and steel structures is discussed.

\section{Modeling Method of Parametric Family Based on Revit}

Parametric family modeling refers to the creation of a Revit family with variable parameters from components with high repetition rate in the project, in order to improve the reuse rate of components and the efficiency of BIM forward design.

The significance of parametric family building lies in that it can adapt to project requirements by input parameter driver family, such as Figure1. The family building process includes the following points for attention:

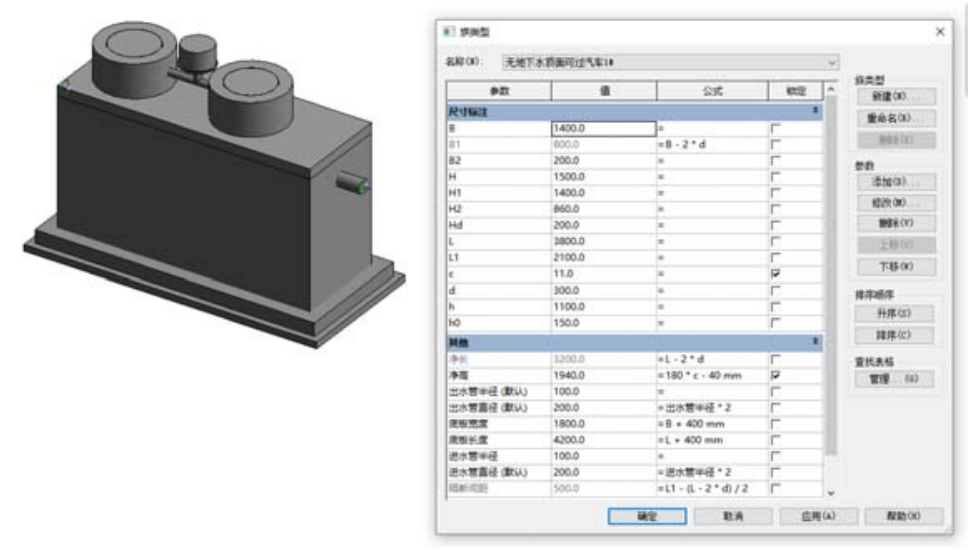

Figure 1. Parametric septic tank family

(1) The selection of family templates plays an important role in the operation of family building. Different types of families in Revit have different properties and creation methods, such as line-based prevention of beams and wall-based prevention of doors and windows. In the planning stage of the model standardization scheme, it is very important to analyze the category of the family and the way to create it in advance.

(2) Drawing the reference plane in advance is the most common method to drive the geometric size of the family by driving the reference plane. The entities of the direct driving family often have too many constraints.

(3) Mechanical and electrical equipment or pipes connected with structures usually require piping connections. The existence of connectors makes the pipeline model easier to capture.

(4) Nested family needs to set the family parameters of nested objects as instance parameters, otherwise it may not be able to associate with the family parameters of nested objects.

\section{Assembled PC Components}

(1) Modeling method

In the design of this project, PC component assembled enclosure is adopted, the enclosure is linearly arranged, the construction column is set every $3 \mathrm{~m}$, and the expansion joint is set every $15 \mathrm{~m}$. According to the characteristics of assembly, it is suitable to use standardized module to model, that is, to pre-assemble quasi-wallboard and several standard columns in nested family, and then load them into the project for final assembly.

Firstly, all kinds of components of fabricated fences are constructed into families. The types of families are shown in Table 1. In the pre-assembly process, the standard elements of wallboard, standard columns, corner columns and expansion joints are loaded into the site model, and finally the rapid layout is completed by using the array method, such as Figure 2. 
Table 1. Component List of Assembled Wall

\begin{tabular}{lll}
\hline Type & Component & Note \\
\hline wallboard & prefabricated wallboard & \\
plinth & prefabricated plinth & \\
pressing & wall roof pressing & \\
& column top pressing & \\
column & standard column & \\
& corner post & for standard columns \\
embedded parts & expansion joint column & for corner columns \\
& $\mathrm{M}-1$ & for expansion joint columns \\
\hline
\end{tabular}
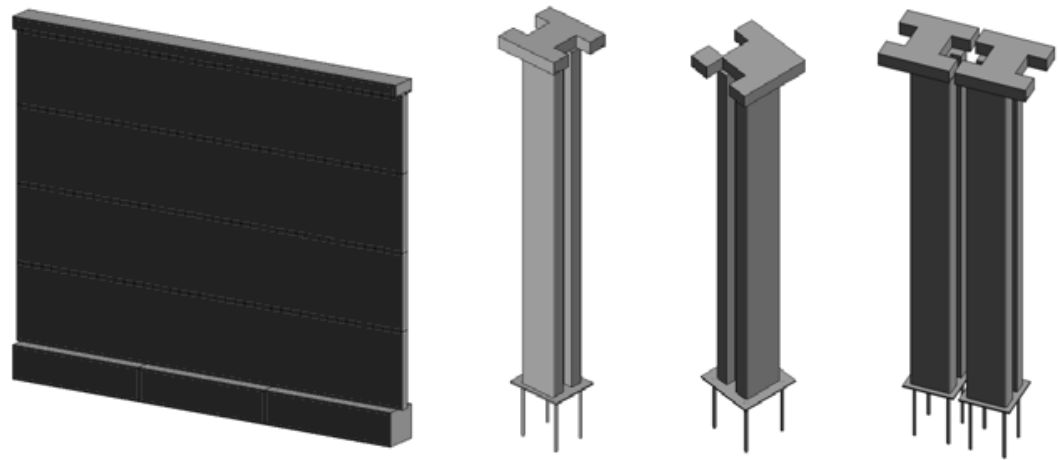

(a) wallboard

(b) standard columns

(c) corner columns (d)

(d) expansion joint columns

Figure 2. Prefabricated Components of Assembled Wall

(2) Advantages

Standardized module splicing can greatly save modeling time and improve modeling efficiency. In addition, the model can be used to conveniently count the number of components and the amount of materials used. If component changes are involved in the design process, the whole site can be adjusted by modifying the unit components or individual components.

(3) Extended application

Because the layout of fabricated fence is mostly linear, the coordinates of the base points of each fence unit can be processed to form a two-dimensional array by dynamo in the modeling process, and the fence automatic splicing can be completed by dynamo program.

\section{Summary of Tekla Modeling}

Tekla software is often used to deepen the modeling of steel structure. Deepening the design of steel structure by Tekla software can highlight the high efficiency and fine characteristics of BIM. Tekla system has various sizes and basic geometric parameters of section steel which are common in the market. At the same time, it presupposes a large number of parameterized nodes, and can set user nodes freely. Under the premise of accurate geometric size, the node model can also set and modify the details of bolts, welds, ribs, cushion plates and so on. Compared with Revit, it can better meet the fine requirements of modeling.

\section{Connection Joints of Steel Structures}

I-beam and square steel pipe are used as structural columns in distribution plant building, and I-beam is used as main stress component in main girder and secondary girder, and support is installed at some beam-column connection joints to enhance connection stiffness. The construction of beam-column joints and beam-beam joints in the whole installation building is highly standardized. For beams of different heights, only the number of bolt holes is adjusted. In the process of modeling, the beam of different height ranges corresponds to the connection nodes of different conditions by presupposing the connection conditions of the nodes, so as to realize the automatic connection of the whole 
building nodes. After the connection is completed, some nodes are manually adjusted or modified by users to meet the design requirements ${ }^{[3]}$, such as Figure 3.
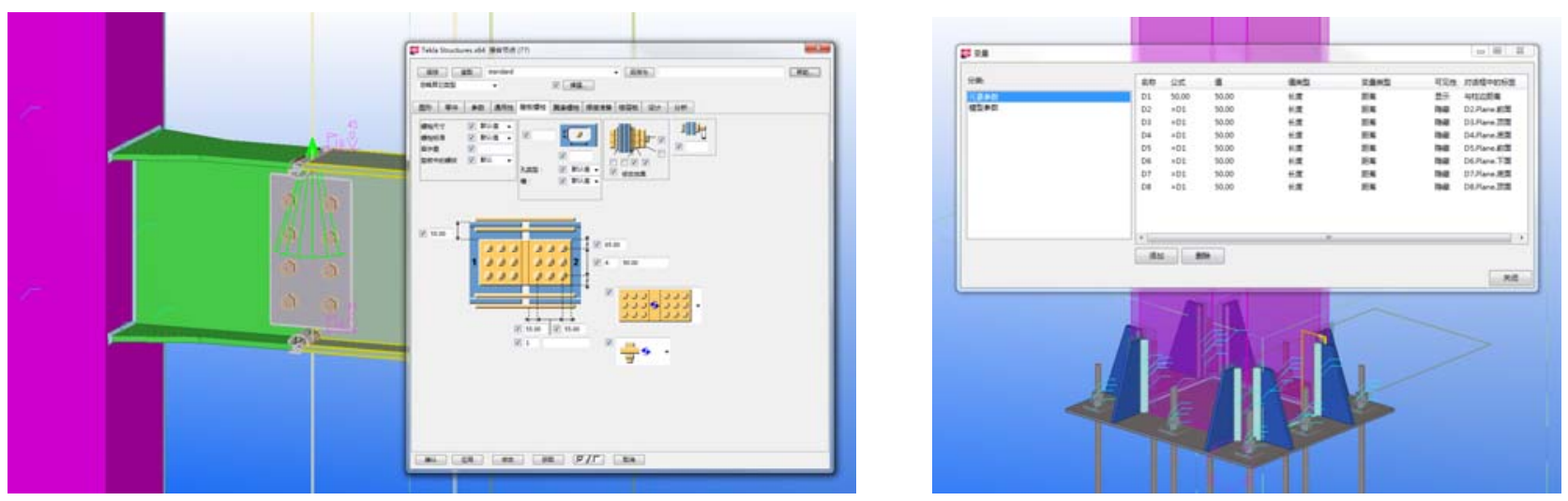

Figure 3. Beam-column Joint Information

Figure 4. Pillar Base Plate Joints and Parameterized Settings

\section{Steel Structure and Concrete Joints}

The column foot of the structural steel tube column is connected with the independent foundation by anchor bolts. The concrete foot is arranged from the foot of the column to $450 \mathrm{~mm}$ above the ground. The foot of the column is connected with the steel column by bolts. Based on the special design requirements, the steel column base plate joints are designed with parametric joints. The spacing of ribs and the size of ribs are modified for different column types, and user nodes are set up to facilitate the rapid addition and use of each column base joints, as shown in the Figure 4.

\section{Reinforcement Bars for Concrete Foundations, Beams and Walls}

The underground part of the structure mainly consists of concrete independent foundation, concrete connecting beam and concrete shear wall of cable well. The connection and anchorage structure of each concrete member is complex, and the reinforcement is not easy to arrange. The cage formed by the longitudinal reinforcement at the foot of the steel column and the stirrups and the reinforced bar of the strong beam are easy to collide with each other, and the longitudinal reinforcement of the strong beam can not extend into the square steel pipe column, so it is necessary to complete the anchorage at the foot of the column. In view of the complex arrangement of reinforcing bars, several collision checks are carried out during the modeling process to ensure that the spacing between reinforcing bars is maintained within a reasonable range, and to provide guarantee for the deepening design of field construction. As shown in the Figure 5.

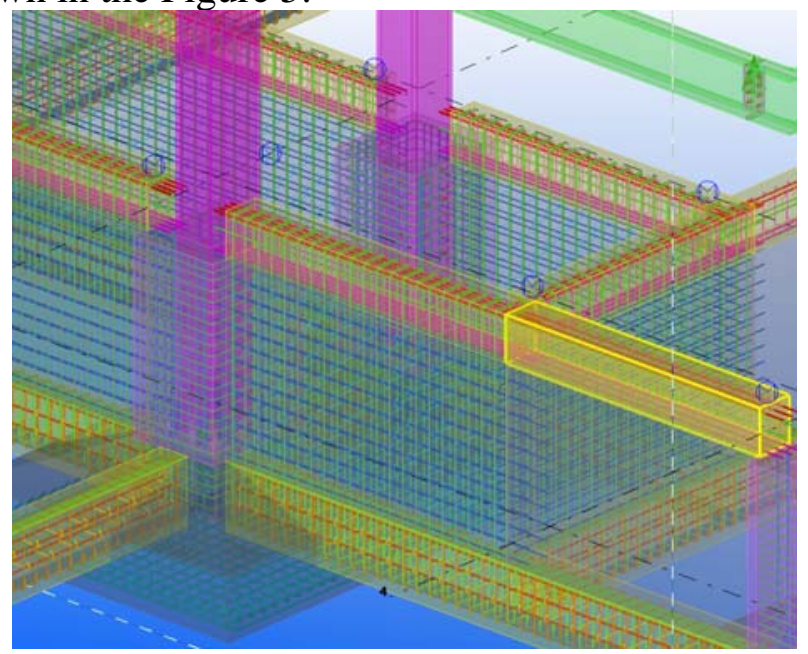

Figure 5. Deepening Design of Reinforcement Bar in Underground Part 


\section{Model Integration}

\section{Model Integration by Using Revit}

Revit three-dimensional model can play a very good role in presenting the final state of the scene, and most of the roaming and demonstration software in the model only supports the use of Revit model, so it is necessary to merge the model in Revit software. Tekla model can interact with various types of modeling software through IFC format files, such as Figure 6. IFC (Industry foundation classes) is a data description standard for construction products formulated by the International Collaborative Alliance for the construction industry. It is widely recognized as an international public data format standard in the construction industry and a bridge between various BIM model software ${ }^{[4]}$.

IFC format is used as a medium to transfer model between different BIM software. The most common problem is component loss and component information loss. This situation in Tekla software is usually caused by view selection errors. When the model exports IFC files, the Coordination View 1.0 or Surface geometry format is selected. The integrity of the exported model will be guaranteed when it enters Revit ${ }^{[5]}$.

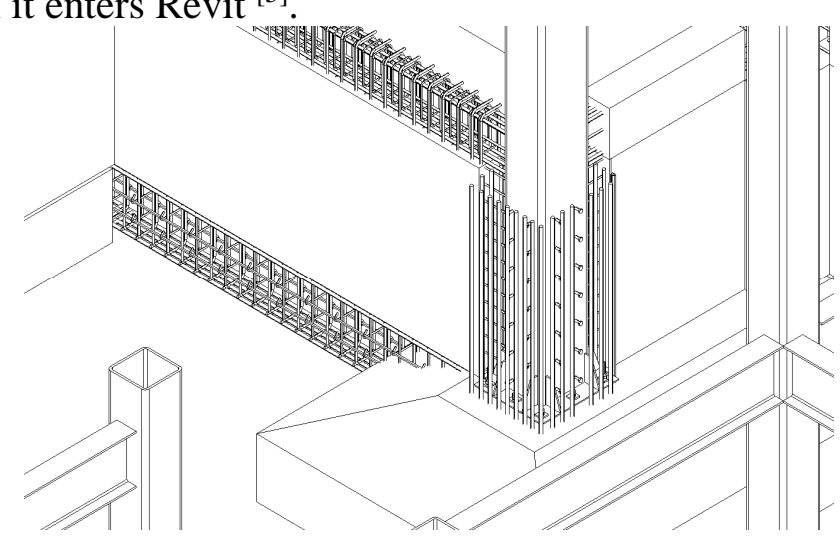

Figure 6. Modeling of Tekla Steel Structure Deepening Model and Building Model in Revit

\section{Model Integration by Using Navisworks}

Navisworks is a lightweight BIM software developed by Autodesk. It supports the model format of most three-dimensional modeling software on the market and has powerful model browsing and collision detection functions. Through the integration of structural model and building model, collision detection of existing models can be carried out, defects can be optimized in real time, rework can be avoided, and construction efficiency can be improved.

Firstly, the model in each software is unified with the origin coordinates, then the model in Revit is exported to *. NWC format, and the model in Tekla is exported to IFC format. Finally, the model is imported into Navisworks for module combination, as shown in the Figure 7. This method can significantly improve the speed of software operation.

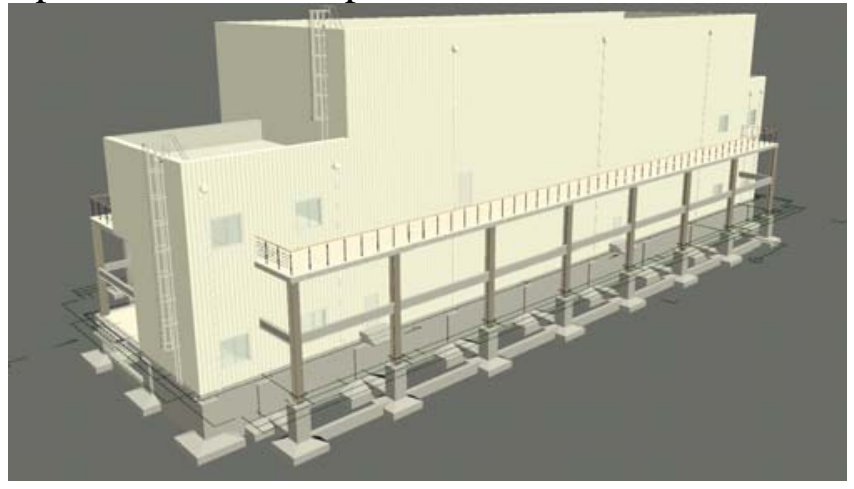

Figure 7. Integrated Model 


\section{Conclusion}

(1) Modeling software Revit and Tekla have their own advantages in BIM modeling. The former is easy to modify model components and can be well integrated with most commercial platforms, but it is difficult to refine itself in the deepening design of steel structures, especially to achieve free connection between special-shaped components. The latter presupposes multi-nodes in steel structure modeling, and the model deepens quickly, which is more suitable for complex steel structure joint modeling. However, the corresponding information of Tekla model needs to be adjusted manually after it is imported into Revit.

(2) Tekla model can be integrated with Revit and Navisworks. Revit internal reference and binding model speed is slower, but it can operate the model components independently, or link to other video rendering software through Revit to further operate the model; while Navisworks integrated model speed is faster, model integrity is better, and components can be added material, but it is difficult to operate a single component. In addition, after importing the BIM model into Navisworks, the file format can be transformed according to the needs of different platforms to realize online browsing and use of the model.

(3) For the fabricated substation, which is composed of concrete and steel structures, a variety of software hybrid modeling methods can be used to improve the efficiency and precision of BIM modeling. That is to say, the site and concrete structure model are built by Revit, and the overall framework is built quickly; the refined model of steel component joints (including bolts, welds and other parts) is built by Tekla, and the list is generated according to the amount of steel used to provide the investment budget reference for the owner unit. Through data exchange and integration, the two models can be networked through the platform to provide necessary support for project management and operation and maintenance data acquisition.

\section{Acknowledgement}

The work of this paper is supported by the research project of Jibei Electric Power Co., Ltd. Project Name: Application of BIM technology in modular substation buildings and structures and Research on assembly materials based on construction conditions in northern Hebei. Project number: SGJBJY00SJS1900039

Thanks to Jun Mao, Zhi Chai, Xiang Li and Shuqiang Qu from Beijing Jiaotong University for their help in this research.

\section{References}

[1] Yu FU, Wei LI, Zhi-guo FANG. Application and Countermeasures of BIM technology in the construction of assembled houses [J]. Urban Housing, 2014 (011): 102-105.

[2] Ai-min SONG, Yu-qi FENG, Jun LU. Application and management of BIM in fabricated buildings [J]. engineering management, 2018.9:186, 194.

[3] Qian-li MA, Fu-ping ZHANG, Yan-hong XU. Intelligent design program for steel structural joints based on Tekla [J]. Industrial automation and intelligent building 2019 (03, 2019): 55-58.

[4] Yong WANG, Jian-ping ZHANG, Zhen-zhong HU. Research on IFC Data Description Standards for Construction [J]. Information Technology for Civil Engineering, 2011, 3(4): 9-15.

[5] Ya-lei XU, Hui-fa CAO, Li-zhi SONG. Analysis of Data Integrity when Tekla Structure Model is imported into Revit in BIM of Steel Structure [J]. Progress of Building Steel Structure, 2018 (05, 2018): 104-108. 